\title{
Reduced expression of multiple gap junction proteins is a feature of cervical dysplasia
}

\author{
Trond Aasen*1,2,3, Sheila V Graham ${ }^{2}$, Mike Edward ${ }^{1}$ and \\ Malcolm B Hodgins ${ }^{1}$
}

Address: ${ }^{1}$ Squamous Cell Biology and Dermatology, Division of Cancer Sciences and Molecular Pathology, Robertson Building, University of Glasgow, 56 Dumbarton Road, Glasgow, G11 6NU, Scotland, UK, ${ }^{2}$ Institute of Biomedical and Life Sciences, Division of Virology, University of Glasgow, Church Street, Glasgow, G11 6JR, Scotland, UK and ${ }^{3}$ Centre for Cutaneous Research, Institute of Cell and Molecular Science, Queen Mary University of London, 4 Newark Street, Whitechapel, London E1 2AT, UK

Email: Trond Aasen* - t.aasen@qmul.ac.uk; Sheila V Graham - sheila.graham@bio.gla.ac.uk; Mike Edward - m.edward@clinmed.gla.ac.uk; Malcolm B Hodgins - m.b.hodgins@clinmed.gla.ac.uk

* Corresponding author

Published: 09 August 2005

Molecular Cancer 2005, 4:31 doi:10.1।86/1476-4598-4-31
Received: 16 April 2005

Accepted: 09 August 2005

This article is available from: http://www.molecular-cancer.com/content/4/I/31

(C) 2005 Aasen et al; licensee BioMed Central Ltd.

This is an Open Access article distributed under the terms of the Creative Commons Attribution License (http://creativecommons.org/licenses/by/2.0), which permits unrestricted use, distribution, and reproduction in any medium, provided the original work is properly cited.

\begin{abstract}
Cervical dysplasia is a premalignant lesion associated with human papillomavirus (HPV) infection which, over time, can turn cancerous. Previous studies have indicated that loss of gap junctions may be a feature of cervical cancer and premalignant dysplasia. Loss of the gap junction protein connexin43 has been demonstrated in dysplastic cervix, but other connexins have not been investigated. In contrast we previously showed that HPV-associated cutaneous warts - and other hyperproliferative skin conditions - display a dramatic upregulation of certain connexins, in particular connexin26. By performing immunofluorescence staining after antigen retrieval of paraffin-embedded cervical tissue samples, this study reports for the first time that connexin 26 and connexin30, in addition to connexin43, are expressed in differentiating cells of normal human cervical epithelia. Moreover, in dysplastic ectocervix, all connexins studied display a dramatic loss of expression compared to adjacent normal epithelia. The role of connexins in keratinocyte differentiation and carcinogenesis is discussed.
\end{abstract}

\section{Findings}

Connexins, a family of 20 trans-membrane proteins in humans, comprise the main subunits of gap junctions specialised clusters of intercellular channels that allow adjacent cells to directly share ions and hydrophilic molecules of up to $\sim 1 \mathrm{KDa}$ in size [1]. Gap junctional intercellular communication (GJIC) is thought to control tissue homeostasis and to coordinate cellular processes such as proliferation, migration and differentiation. Disruption of GJIC or mutations in connexins is associated with several human diseases such as hearing loss, neuropathies and various skin conditions [2].

There is also substantial evidence that connexins have a tumour suppressor role [reviewed in [3]]. While reduced or aberrant GJIC or connexin expression has been found in some tumours and in many tumour cell lines [4-7], restoration of GJIC in tumour cell lines by connexin 
transfection can reduce growth and tumourigenicity [810]. However, the tumour suppressive effects may be tissue and connexin-specific $[11,12]$ and also appear to involve non-gap junctional properties of connexins [1315]. Moreover, it has been observed that connexin expression (especially connexin26) is often upregulated in hyperplastic tissues including psoriatic epidermis and viral warts [16], benign prostatic hyperplasia [17], and mouse papillomas [18]. While induction of connexin26 and connexin 43 has also been observed in metastatic breast carcinomas [19], others have reported that connexin 26 and connexin 43 are downregulated in mammary carcinoma cell lines and re-expression of these connexins leads to repression of tumour-forming ability [20]. Although potent tumour promoters markedly downregulate GJIC in cultured cells [21], intact skin painted with tumour promoters such as 12-O-tetradecanoylphorbol 13-acetate (TPA) show a dramatic upregulation of connexin 26 and connexin43 expression [22-24]. Moreover, several reports have shown a negative correlation between expression of connexins and cell diapedesis and or tumour metastasis, including brain tumours $[25,26]$, melanoma [27], breast carcinoma [28] and lung squamous cell carcinomas [29]. Thus, although connexins act as tumour suppressor genes in several types of cancers, the role of connexins in metastasis are more conflicting.

The association of certain "high risk" human papillomaviruses (HPVs) with the development of cervical cancer on the other hand has been clearly demonstrated [30], with several targets and functions of the viral oncoproteins identified [31]. However, tumour progression only occurs in a very small subpopulation of HPV infected individuals; thus, it is thought that several molecular and cellular changes are required over time for malignant conversion to take place. One of these cellular changes may be loss of connexin expression and/or GJIC. Indeed, it was observed more than four decades ago, using freeze-fracture electron microscopy, that normal cervix has abundant gap junctions, and that these are deficient in cervical carcinomas [32]. Further work also demonstrated a dramatic decrease of gap junction plaques in pre-malignant conditions such as severe dysplasia [33]. More recently, immunohistochemistry of cervical biopsies showed reduced connexin43 expression in dysplastic regions compared to normal epithelia [34] and work in-vitro has suggested that loss of GJIC may be an early event in papillomavirus associated cell transformation [35-38]. However, this may be limited to certain cell types or to particular oncogenes that are not always expressed during tumour progression (for example the E5 oncogene product that is frequently deleted after viral integration). Recently, we also showed that human cervical keratinocytes harbouring HPV-16 expressed several connexins (including connexin26, connexin30 and connexin43), and displayed extensive
GJIC that was only lost at a late malignant stage [39]. This, together with our observation of a dramatic upregulation of connexin26 expression in cutaneous HPV warts [16], prompted us to investigate the expression pattern of several connexins in normal and dysplastic cervical epithelia.

Six duplicate slides of HPV-16 positive dysplastic cervix (cervical intraepithelial neoplasia (CIN) I, CIN I/II, and CIN III) were obtained from Dr. John Doorbar (Dr Karl Sotlar Institute for Pathology, Tubingen Germany, as previously described [40]). Antigen retrieval using pressure cooking in citrate buffer was performed followed by immunofluorescence staining using antibodies and methods as previously described [39]. All antibodies were diluted in PBS containing 1\% bovine serum albumin (BSA), $0.1 \%$ Tween-20 and $0.01 \%$ SDS, and incubated overnight at $4{ }^{\circ} \mathrm{C}$. The presence of BSA and SDS was used to improve the connexin staining as previously shown for other antibodies [41]. Sections were mounted with Vectashield mounting medium containing DAPI and all images were obtained using an upright Zeiss Axioplan 2 fluorescence microscope. After immunofluorescence imaging the slides were washed and stained with Haematoxylin and Eosin (H\&E) to verify previous CIN gradings.

As seen in Figure 1A, all sections of normal ectocervix expressed connexin43 (red) mainly in the suprabasal spinous layers. Some staining was also seen in the basal layer although it was difficult to identify specific gap junction plaques. Connexin26 and connexin 30 were found mainly in the upper spinous layers, but some was also detected in the lower layers similar to connexin43, particularly with connexin30 (1A and 1B). Overlapping colocalisation (yellow gap junction plaques) was seen in connexin26/connexin43 triple-immunofluorescence staining experiments (Figure 1A) as observed in palmoplantar skin [42]. The more differentiated cervical squames were negative for all three connexins. Moreover, no definite connexin membrane plaques could be identified in the basal layer although some gap junction plaques are likely to be present as previously shown in early freezefracture electron microscopy studies [32,33]. As expected, the proliferation marker Ki-67 was detected in basal or suprabasal keratinocytes but not in differentiated cells (Figure 1B).

In contrast, all sections of dysplastic cervix displayed loss of protein expression of all three connexins investigated (Figure 1C-F). Connexin26 and connexin30 expression was completely absent in the CIN3 lesions (Figure 1C). In some areas however, particularly using high magnification power and high laser exposure, some connexin 43 plaques could be seen in dysplastic areas, although it was difficult to assess accurately the dysplasia in those exact areas (Figure 1D-E). Some small connexin30 gap 

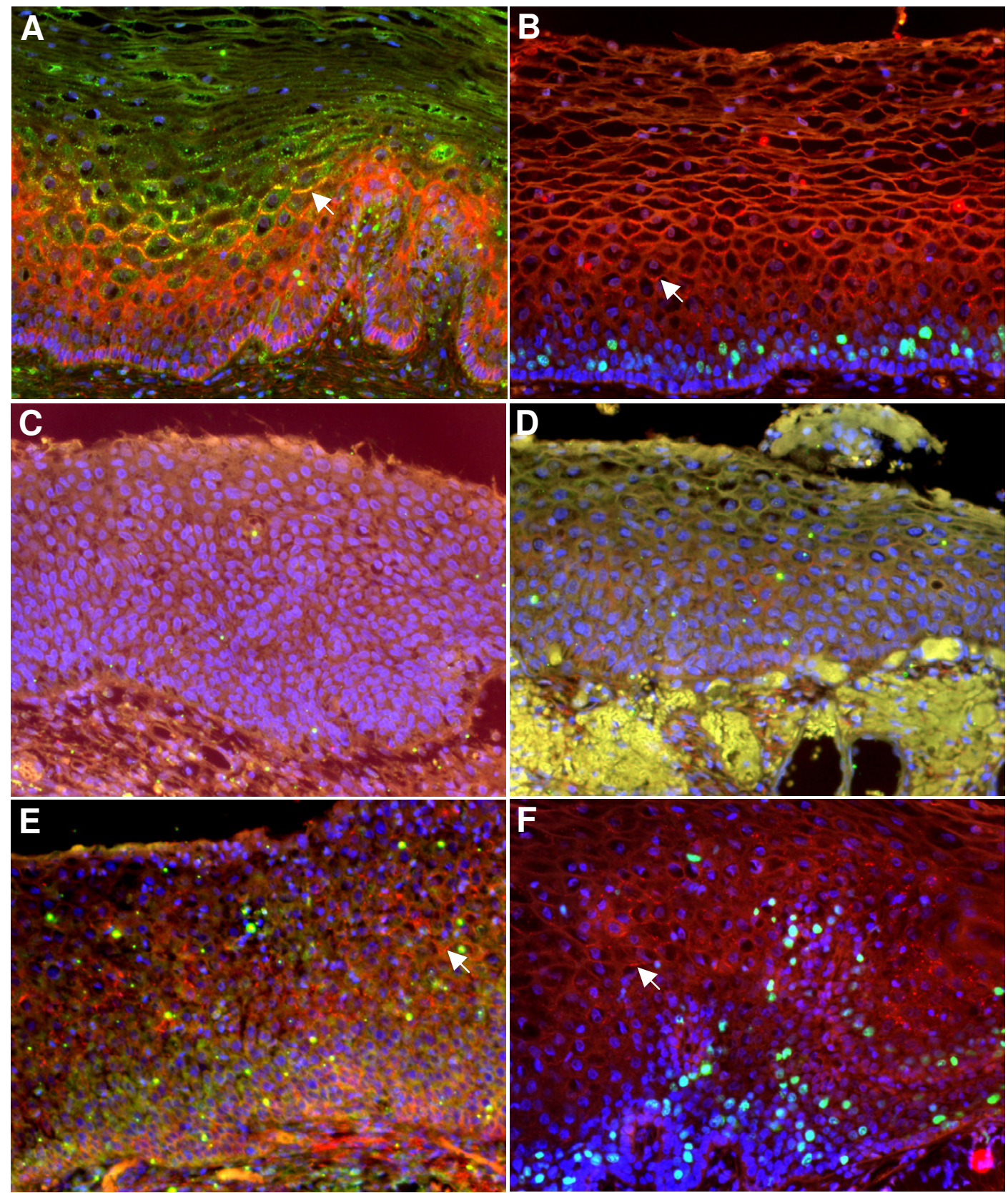

Figure I

Connexin expression in normal and dysplastic human cervical epithelium. All nuclei are stained with DAPI (blue). A: All normal ectocervical tissue sections revealed positive staining of connexin43 gap junctions (red) particularly in the spinous layers. Connexin 26 was also positive (green), particularly in upper spinous and more superficial layers. Overlapping expression of connexin43 and connexin26 was observed (yellow) and these areas displayed particularly large gap junction plaques (arrow). B: Connexin30 (red) displayed a similar staining pattern to Connexin26 although gap junction plaques were more frequently observed in lower spinous layers (arrow). In these normal sections, the proliferation marker Ki-67 was detected (turquoise) in basal and immediate suprabasal layers only, as expected. (C) In all premalignant CIN III sections there was complete absence of connexin26 (green) and connexin30 (red). D: In one CIN III lesion, small amounts of connexin43 (red) were present, mainly as diffuse cytoplasmic staining, but no positive connexin26 staining was detectable (green). E: In CIN I/II lesions no clear connexin26 gap junctions were present (green) whereas several connexin43 plaques were visible (arrow), but in a less homogenous fashion compared to normal ectocervix. F: Connexin30 gap junctions were clearly detected in areas of low grade CIN I lesions, although they tended to occur in stratified regions of cell differentiation (arrow) rather than areas of abnormal cellular proliferation (Ki-67, turquoise) and atypical cellular crowding. 
junction plaques were also identified in dysplastic tissue, but generally these appeared separate from cells positive for the proliferation marker Ki-67 in stratified cells of dysplastic cervix (Figure 1F). Thus, although some connexin 30 and connexin 43 gap junction plaques were occasionally seen in low grade CIN I/II cervical biopsies, there was always a dramatic loss of connexin expression compared to adjacent normal tissue.

In conclusion, this report demonstrates for the first time the presence of connexin 26 and connexin 30 gap junction plaques, as well as connexin 43 , in human ectocervix, displaying a similar staining pattern to that observed for connexin26 in vaginal epithelium [16]. Moreover, dysplastic areas of the biopsies show a dramatic loss of gap junction plaques, primarily due to reduced expression rather than cytoplasmic accumulation of connexin proteins. However, it cannot be excluded that cytoplasmic connexins are undetectable by the current staining protocol and antibodies available. The use of paraffin embedded tissue may reduce the detection efficiency of smaller gap junction plaques and/or cytoplasmic proteins. Some general background immunofluorescence is present in both normal and dysplastic tissue and this also hampers detection of cytoplasmic proteins. Significantly however, lack of staining in dysplastic lesions cannot be attributed to sample or patient factors, as the staining of both normal and dysplastic tissue were performed using the same tissue biopsies. It thus also appears that the lack of gap junctions in CIN lesions are likely to be controlled in an intracrine fashion rather than as an effect of paracrine or hormonal fashion, particularly since areas of gap junction plaques where observed in differentiating cells layered in between dysplastic/Ki-67 positive cells. Currently very little is known regarding how connexin gene expression is regulated and further studies, perhaps using laser capture followed by RT-PCR and/or methylation specific PCR, are required to elucidate what regulates the overexpression and loss of connexins, in cutaneous warts and CIN lesions respectively. Our previous work on model cell lines indicate that a combination of cytoplasmic connexin accumulation and loss of connexin transcription may occur [39].

Expression of connexin26 but not connexin 40 and connexin 43 has been shown to reduce tumourigenesis of HeLa cells (cervical tumour cells) [12]. It is also likely that other connexins are expressed in human ectocervix, for example connexin 31 which is expressed in differentiating keratinocytes in the epidermis [43], and may play a different role in epidermal biology and carcinogenesis. In order to answer some of these outstanding questions, it is imperative to decipher more accurately what biological role gap junctions and individual connexins execute.
These results are clearly in disparity to observations in interfollicular epidermis, where connexin26 and connexin 30 are normally not present (apart from palmoplantar skin) but becomes highly expressed in areas of hyperproliferation such as viral warts [16]. The reason for this remains unknown, but several factors may contribute. For example, the stratifying cervical epithelium is of nonkeratinising nature. Unlike dysplastic cervical epithelia, cutaneous warts are typically highly proliferative, thick lesions, and there is some evidence that the presence of gap junctions may favour such stratification (perhaps due to metabolic co-operation) [39]. Conversely, it is currently difficult to explain why gap junctions are lost in HPV-16 positive CIN lesions. It is clear however that basal keratinocytes express at least tenfold fewer gap junction plaques than differentiated keratinocytes $[32,33]$, and the lack of gap junctions in CIN lesions may simply reflect failure of keratinocyte differentiation in the stratified layers. Although there is some evidence, it remains to be seen whether connexins themselves play a direct role in regulating keratinocyte differentiation. Loss of connexin expression may also be associated with HPV infection, although our recent results suggests that such correlation requires high levels of oncogene expression and/or a further malignant progressed state [39]. A viral advantage associated with loss of GJIC has not been described, however a recent intriguing report has documented gap-junction-mediated immunological coupling allowing direct transfer of antigenic peptides [44] which may be involved in ensuring proper antigenic T-cell response against viruses such as HPV hiding in cells or expressing antiapoptotic proteins.

\section{Authors' contributions}

TA carried out all experimental assays and drafted the manuscript. TA, MBH, ME and SVG participated in study design and coordination, data interpretation and manuscript preparation. All authors read and approved the final manuscript.

\section{Acknowledgements}

Dr. John Doorbar kindly provided the CIN-graded paraffin embedded tissue sections (Dr Karl Sotlar Institute for Pathology, Tubingen Germany, obtained as previously described [40]). We are grateful to Dr Edgar Rivedal for supplying the connexin43 antibody. TA was supported by a University of Glasgow Medical Faculty Postgraduate Research Scholarship and by a postgraduate training grant from Roche products.

\section{References}

I. Kumar NM, Gilula NB: The gap junction communication channel. Cell 1996, 84:381-388.

2. Kelsell DP, Dunlop J, Hodgins MB: Human diseases: clues to cracking the connexin code? Trends Cell Biol 200I, I I:2-6.

3. Trosko JE, Ruch RJ: Cell-cell communication in carcinogenesis. Front Biosci 1998, 3:D208-D236.

4. Saito T, Nishimura M, Kudo R, Yamasaki H: Suppressed gap junctional intercellular communication in carcinogenesis of endometrium. Int J Cancer 2001, 93:3 I 7-323. 
5. Saitoh M, Oyamada M, Oyamada Y, Kaku T, Mori M: Changes in the expression of gap junction proteins (connexins) in hamster tongue epithelium during wound healing and carcinogenesis. Carcinogenesis 1997, I 8:1319-1328.

6. Holden PR, McGuire B, Stoler A, Balmain A, Pitts JD: Changes in gap junctional intercellular communication in mouse skin carcinogenesis. Carcinogenesis |997, I8:|5-2|

7. Laird DW, Fistouris P, Batist G, Alpert L, Huynh HT, Carystinos GD, Alaoui-Jamali MA: Deficiency of connexin43 gap junctions is an independent marker for breast tumors. Cancer Res 1999, 59:4104-4II0

8. Saunders MM, Seraj MJ, Li Z, Zhou Z, Winter CR, Welch DR, Donahue $\mathrm{HJ}$ : Breast cancer metastatic potential correlates with a breakdown in homospecific and heterospecific gap junctional intercellular communication. Cancer Res 200I, 6I:1765-1767.

9. Zhang ZQ, Zhang W, Wang NQ, Bani-Yaghoub M, Lin ZX, Naus CC: Suppression of tumorigenicity of human lung carcinoma cells after transfection with connexin43. Carcinogenesis 1998, 19:|889-|894.

10. Huang RP, Fan Y, Hossain MZ, Peng A, Zeng ZL, Boynton AL: Reversion of the neoplastic phenotype of human glioblastoma cells by connexin 43 (cx 43). Cancer Res 1998, 58:5089-5096.

II. Yano T, Hernandez-Blazquez FJ, Omori Y, Yamasaki H: Reduction of malignant phenotype of HEPG2 cell is associated with the expression of connexin $\mathbf{2 6}$ but not connexin 32. Carcinogenesis 200I, 22:1593-1600

12. Mesnil M, Krutovskikh V, Piccoli C, Elfgang C, Traub O, Willecke K, Yamasaki H: Negative growth control of HeLa cells by connexin genes: connexin species specificity. Cancer Res 1995, 55:629-639.

13. Moorby C, Patel M: Dual functions for connexins: Cx43 regulates growth independently of gap junction formation. Exp Cell Res 200I, 27I:238-248.

14. Krutovskikh VA, Troyanovsky SM, Piccoli C, Tsuda H, Asamoto M, Yamasaki H: Differential effect of subcellular localization of communication impairing gap junction protein connexin43 on tumor cell growth in vivo. Oncogene 2000, 19:505-513.

15. Qin H, Shao Q, Curtis H, Galipeau J, Belliveau DJ, Wang T, AlaouiJamali MA, Laird DW: Retroviral delivery of connexin genes to human breast tumor cells inhibits in vivo tumor growth by a mechanism that is independent of significant gap junctional intercellular communication. J Biol Chem 2002.

16. Lucke T, Choudhry R, Thom R, Selmer IS, Burden AD, Hodgins MB: Upregulation of connexin $\mathbf{2 6}$ is a feature of keratinocyte differentiation in hyperproliferative epidermis, vaginal epithelium, and buccal epithelium. J Invest Dermatol 1999, I I 2:354-36 I.

17. Habermann H, Ray V, Habermann W, Prins GS: Alterations in gap junction protein expression in human benign prostatic hyperplasia and prostate cancer. J Urol 2002, 167:655-660.

18. Sawey MJ, Goldschmidt MH, Risek B, Gilula NB, Lo CW: Perturbation in connexin 43 and connexin 26 gap-junction expression in mouse skin hyperplasia and neoplasia. Mol Carcinog 1996, I7:49-6I.

19. Jamieson S, Going JJ, D'Arcy R, George WD: Expression of gap junction proteins connexin 26 and connexin 43 in normal human breast and in breast tumours. J Pathol 1998, 184:37-43.

20. Hirschi KK, Xu CE, Tsukamoto T, Sager R: Gap junction genes Cx26 and Cx43 individually suppress the cancer phenotype of human mammary carcinoma cells and restore differentiation potential. Cell Growth Differ 1996, 7:861-870.

21. Brissette JL, Kumar NM, Gilula NB, Dotto GP: The tumor promoter 12-O-tetradecanoylphorbol-13-acetate and the ras oncogene modulate expression and phosphorylation of gap junction proteins. Mol Cell Biol I99I, I I:5364-537I.

22. Budunova IV, Carbajal S, Slaga TJ: The expression of gap junctional proteins during different stages of mouse skin carcinogenesis. Carcinogenesis 1995, 16:2717-2724.

23. Risek B, Pozzi A, Gilula NB: Modulation of gap junction expression during transient hyperplasia of rat epidermis. I Cell Sci 1998, III ( Pt 10): I395-I 404.

24. Budunova IV, Carbajal S, Slaga T]: Effect of diverse tumor promoters on the expression of gap-junctional proteins connexin (Cx)26, Cx3I.I, and Cx43 in SENCAR mouse epidermis. Mol Carcinog 1996, I5:202-2।4.
25. Lin JH, Takano T, Cotrina ML, Arcuino G, Kang J, Liu S, Gao Q, Jiang L, Li F, Lichtenberg-Frate H, Haubrich S, Willecke K, Goldman SA, Nedergaard M: Connexin 43 enhances the adhesivity and mediates the invasion of malignant glioma cells. J Neurosci 2002, 22:4302-43II I.

26. Oliveira R, Christov C, Guillamo JS, Debouard S, Palfi S, Venance L, Tardy M, Peschanski M: Contribution of gap junctional communication between tumor cells and astroglia to the invasion of the brain parenchyma by human glioblastomas. BMC Cell Biol 2005, 6:7.

27. Ito A, Katoh F, Kataoka TR, Okada M, Tsubota N, Asada $H$, Yoshikawa K, Maeda S, Kitamura Y, Yamasaki H, Nojima H: A role for heterologous gap junctions between melanoma and endothelial cells in metastasis. J Clin Invest 2000, 105: I I89- I 197.

28. Pollmann MA, Shao Q, Laird DW, Sandig M: Connexin 43 mediated gap junctional communication enhances breast tumor cell diapedesis in culture. Breast Cancer Res 2005, 7:R522-R534.

29. Ito A, Koma YI, Uchino K, Okada T, Ohbayashi C, Tsubota N, Okada $M$ : Increased expression of connexin 26 in the invasive component of lung squamous cell carcinoma: Significant correlation with poor prognosis. Cancer Lett 2005.

30. zur Hausen $\mathrm{H}$ : Papillomaviruses and cancer: from basic studies to clinical application. Nature Rev Cancer 2002, 2:342-350.

31. Longworth MS, Laimins LA: Pathogenesis of human papillomaviruses in differentiating epithelia. Microbiol Mol Biol Rev 2004, 68:362-372.

32. McNutt NS, Weinstein RS: Carcinoma of the cervix: deficiency of nexus intercellular junctions. Science 1969, 165:597-599.

33. McNutt NS, Hershberg RA, Weinstein RS: Further observations on the occurrence of nexuses in benign and malignant human cervical epithelium. J Cell Biol I97I, 5 I:805-825.

34. King TJ, Fukushima LH, Hieber AD, Shimabukuro KA, Sakr WA, Bertram JS: Reduced levels of connexin 43 in cervical dysplasia: inducible expression in a cervical carcinoma cell line decreases neoplastic potential with implications for tumor progression. Carcinogenesis 2000, 21:1097-1 109.

35. Ennaji MM, Schwartz JL, Mealing G, Belbaraka L, Parker C, Parentaux $\mathrm{M}$, Jouishomme $\mathrm{H}$, Arella M, Whitfield JF, Phipps J: Alterations in cell-cell communication in human papillomavirus type 16 (HPV 16) transformed rat myoblasts. Cell Mol Biol (Noisy -legrand) 1995, 41:48I-498.

36. Oelze I, Kartenbeck J, Crusius K, Alonso A: Human papillomavirus type $16 \mathrm{E} 5$ protein affects cell-cell communication in an epithelial cell line. J Virol 1995, 69:4489-4494.

37. Tomakidi P, Cheng H, Kohl A, Komposch G, Alonso A: Connexin 43 expression is downregulated in raft cultures of human keratinocytes expressing the human papillomavirus type 16 E5 protein. Cell Tissue Res 2000, 301:323-327.

38. Faccini AM, Cairney M, Ashrafi GH, Finbow ME, Campo MS, Pitts JD: The bovine papillomavirus type $4 \mathrm{E8}$ protein binds to ductin and causes loss of gap junctional intercellular communication in primary fibroblasts. J Virol 1996, 70:9041-9045.

39. Aasen T, Hodgins MB, Edward M, Graham SV: The relationship between connexins, gap junctions, tissue architecture and tumour invasion, as studied in a novel in vitro model of HPV. 16-associated cervical cancer progression. Oncogene 2003, 22:7969-7980.

40. Middleton K, Peh W, Southern S, Griffin H, Sotlar K, Nakahara T, ElSherif A, Morris L, Seth R, Hibma M, Jenkins D, Lambert P, Coleman $N$, Doorbar J: Organization of human papillomavirus productive cycle during neoplastic progression provides a basis for selection of diagnostic markers. J Virol 2003, 77: I0I86-I020 I.

41. Schipper RG, Romain N, Otten AA, Tan J, Lange WP, Verhofstad AA: Immunocytochemical detection of ornithine decarboxylase. J Histochem Cytochem 1999, 47:1395-I 404.

42. Rouan F, White TW, Brown N, Taylor AM, Lucke TW, Paul DL, Munro CS, Uitto J, Hodgins MB, Richard G: trans-dominant inhibition of connexin- 43 by mutant connexin-26: implications for dominant connexin disorders affecting epidermal differentiation. J Cell Sci 200I, I | 4:2 I 05-2 I I3.

43. Di WL, Rugg EL, Leigh IM, Kelsell DP: Multiple epidermal connexins are expressed in different keratinocyte subpopulations including connexin 3 I. I Invest Dermatol 200 I, I I 7:958-964.

44. Neijssen J, Herberts C, Drijfhout JW, Reits E, Janssen L, Neefjes J: Cross-presentation by intercellular peptide transfer through gap junctions. Nature 2005, 434:83-88. 